\title{
The Transition from State to Local Funding for Virginia Master Gardener Volunteer Management
}

Sheri D orn ${ }^{1}$ and Paula Diane R elf ${ }^{2}$

AdDitional INDEX WORDS. leadership development, extension

Summary. M anagement changes brought about by 1996 budgetary action shifted local M aster G ardener (M G ) program management from state-funded local agents to a structure of coordinators consisting of locally funded agents, locally funded nonagent coordinators, and volunteers willing to take on additional responsibilities. The V irginia C ooperative Extension (VCE) M G volunteer program is currently available in 76 unit offices. The unit programs are managed by 46 M G coordinators, including 8 locally funded agents, 8 locally funded technicians, and 30 volunteers. C urrently, there are 2747 M G volunteers (trainees, interns, and M G s). To provide consistent, state-level direction and leadership to this less experienced group of local coordinators and to prepare them for their jobs as M G program managers, current management materials were extensively revised and expanded and new resources were developed. These efforts to ensure that everyone understood the purpose and focus of the VCE M G program resulted in revision of M G program policies, development of new volunteer training materials, establishment of a state-level M G planning and work team, new management guidelines, in-service training for coordinators, an administrative website and electronic discussion listserv available only internally to agents and coordinators, and a state M G newsletter focused on the role of M G s as community leaders and educators. 


\section{Changes in Virginia MG management, 1996}

Before 1996, Virginia M G program management was very similar to others reported in Bradshaw's survey (1997). A state extension specialist and paid state coordinator provided support (largely resource materials) to local extension agents who managed the MG programs with a degree of autonomy. M ost states recognize that individual county or unit MG programs need "latitude to design programs to meet their specific needs" (Ruppert et al., 1997). This leads to a certain degree of autonomy at the local level, although "state leadership isnecessary to provide continuity, communication, and resource maximization" (Ruppert et al., 1997). B efore in Virginia, state-funded extension agents, primarily consumer horticulture agents but also some agriculture and 4-H agents, entirely managed local M G programsor delegated responsibilities to established MGs. O ften, $M G$ volunteer managers did not have clear knowledge of VCE's educational mission, theroleof theextension agent, or of their purpose as volunteers recruited to assist VCE meet its goals.

$M$ ajor $M G$ program management changes were brought about in 1996 by state budgetary action. I $n$ an e-mail memo from then-associate director of agriculture and $\mathrm{N}$ atural Resources (Jones, 1996), it was stated that "in response to guidelines and guidance from the Executive Branch, VCE has developed a plan to eliminate the use of state funds to support the M G program, effective 1 July 1996." It was stated that "VCE will continue to use the experience and expertise of M Gs to provideappropriateeducational programs to their communities ... (however) The training and management of $M G$ volunteers cannot be conducted by VCE staff funded with state tax dollars" (J ones, 1996). Therefore, in 1996, all M G management shifted to a structure of local M G coordinators consisting of locally funded agents, locally funded nonagent coordinators, or volunteers willing to take on additional responsibilities.

Although specific reasonsfor these changes were not given, several issues have been attributed to the 1996 budgetary action. In Virginia, as in other states, legislators, thepublic, and some agents had become confused as to whether or not MG volunteers are extension clientele. In some cases, agents with $\mathrm{M} \mathrm{G}$ management responsibilities had focused a significant amount of their efforts on this select group of people without related educational programming being implemented in the community. Some agents, sharing Florida's sentiments that "the volunteers are customers of and very visible ambassadors for (extension)" (Ruppert et al., 1997), had taken efforts to satisfy this vocal group that had a history of influencing budget decisions. Any individual who applied to the program had been accepted, trained, and provided with continued education and one-on-one information regardless of whether or not they could or would volunteer for extension. The quantity of warm bodies in training classes had become far more important in somelocal programsthan the quality of the volunteer and their willingnessand ability to further VCE's mission. I n somecases, M G volunteers required so much of the agent's time that inadequate time was available for designing programs with community impact for M Gs to implement.

Additionally, confusion had developed over therole of the M G volunteer. Through theyears, the role of the MG volunteer has changed from "answer(ing) repetitive, easilyanswered questions by phone or in person" to "involvement in proactive and community-oriented ventures" (Ruppert et al., 1997). In many cases, effective educational programs for the community have resulted. H owever, increased liberties with volunteer jobs has resulted in M Gs in some offices volunteering in jobs outside of extension's education mission, such as becoming free garden labor. With volunteer jobs shifting away from VCE's educational mission, the expected programmatic return for VCE wasnot always satisfactory. Bobbitt (1997) pointed out that the M G program must express a clear mission of education. "M G saretrained to be grassroots educators," serving many diverse audiences, and relating to "the larger issues facing societyenvironmental quality, crime prevention, food security, strong neighborhoods, and healthy, capable children." Without this purpose driving the M G program, the program would "be viewed as little more than a glorified garden club and not worthy of support" (Bobbitt, 1997).
The 1996 budgetary events provided the opportunity to bring statewide focus to the purpose of the VCE $M G$ program. The Office of Environmental $\mathrm{H}$ orticulture $(\mathrm{OEH})$, directed by the state extension Environmental $\mathrm{H}$ orticulture specialist and housing the state M G coordinator and other staff, took leadership in redirecting the M G program. N ew program directions focused on developing M G volunteers as educational partners with and nonpaid staff of VCE. Emphasis was placed on the role of $M G$ s as volunteer educators whose purpose was to conduct VCEsponsored educational programs for their local communities. It was further emphasized that the VCE MG program's purpose was not to provide in-depth horticultural education for gardenerswho simply wanted theextensive education given to $\mathrm{M} \mathrm{G}$ volunteers.

The restructuring based on local M G coordinators was confusing for volunteer and paid staff alike. Coordinators needed information, guidance, and suggestions for meeting their new management responsibilities. Sixty-five percent of local coordinatorswereM G volunteers, most of whom had neither knowledge of managing a volunteer program, nor clear understanding of VCE and the appropriate educational role of $M G$ volunteers. They were familiar with the $M G$ training program from the volunteer perspective, but had no experience managing the program or teaching $M G$ volunteers how to implement VCE public educational programs for the community.

$M$ isunderstanding by agents and VCE administration regarding guidelines and guidance from the Executive Branch created a shift in extension agents' attitudes. Some agents who worked closely with MG programs prior to the 1996 changes were suddenly unwilling to talk to $M G$ volunteers or to involve $M G$ volunteers in public education program implementation, the latter of which was acknowledged and encouraged by the VCE director throughout the 1996 transition. The $O$ ffice of Environmental $\mathrm{H}$ orticulture led efforts to reduce misunderstanding by preparing thenew local coordinatorsfor their jobsasM G program managers and ensuring that everyone, including volunteers and paid VCE staff, understood the purpose and focus of the VCE M G program. Efforts directed at reducing this misunderstanding included the revi- 
Table 1. A listing of chapter titles for the 1998 V C E M aster G ardener Cordinator M anual (Dorn and R elf, 1998b).

\begin{tabular}{ll}
\hline Chapter & Title \\
\hline 1 & The local M G coordinator \\
2 & Virginia Tech affiliation \\
3 & Getting started for the first time \\
4 & Designing and implementing educational programs \\
5 & VCE publication 426-699, Welcome to Virginia M aster Gardening! \\
6 & Establishing responsibilities of M aster G ardeners \\
7 & Developing skills and knowledge \\
8 & Recruiting and selecting prospective VCE M aster gardeners \\
9 & Training: Preparing VCE M G s for their jobs \\
10 & Ensuring continued growth \\
11 & Promoting VCE M G programs \\
12 & M anaging resources \\
13 & E valuating the M G program \\
14 & Recordkeeping and reporting
\end{tabular}

sion of M G program policies, development of new volunteer materials, establishment of a M G team, new management guidelines, in-service training for coordinators, an administrative Website, an electronic discussion list for coordinators, a refocused stateM G newsletter, and training sessions with VCE administrators and district and unit directors.

\section{New VCE MG program policies}

Themanagement changesrequired a formal set of VCE M G program policies to be applied throughout the state with oversight from the state M G coordinator and state extension specialist. Before 1996, policies were developed and mutually agreed upon by agents, but had no university or VCE administrative approval, and thus lacked authority for compliance with the exception of the pesticidepolicy issued by the university's C hemical, D rug, and Pesticide U nit. Because extension agents function with a great degree of autonomy in their unit offices, the authority for local M G program management needed to be transitioned to the new system of local M G coordinators. Receiving V CE administrativeapproval for the revised VCE M G program policies (D orn and Relf, 1997) wasthefirst step in providing authority to the new coordinators of Virginia M G programs. This administrative approval and coordinator authority was necessary to assure effective training and direction to an acknowledged valuablegroup of volunteers and to maintain the volunteers' tie to VCE and thelocal office. Therevised policies included existing policies
(Schwab and Relf, 1989) that were expanded to addressadditional issues. In a series of meetings in N ovember 1996, coordinators (agents, nonagents, and volunteers) were invited to review the proposed policies and make additional suggestions for revision. The new policies were completed, reviewed, and approved by VCE administration in February 1997. Thesenew policiesset forth minimum standards and protocol for recruitment, training, volunteer time, M G volunteer projects, and related topics.

Changes in the program direction and policies required informing and educating all $M G$ volunteers and VCE staff across the state regarding the new standards. Revised materials about being a VCE MG volunteer were developed from prior publications (Schwab and Relf, 1989; Relf, 1994) and the new VCE M G program policies. These revised materials, entitled Welcome to Virginia Master Gardenering! (VCE publication 426699; Dorn and Relf, 1998a), were then printed as part of the Virginia Master Gardener H andbook (Relf, 1994). These revised volunteer materialswere first distributed in draft form to local coordinators in August 1997 for local production and distribution. VCE publication \#426-699 was printed in J anuary 1998 and all VCE M Gs trained in J anuary 1998 or later received copies of the information in their training handbook.

\section{The MG team}

A problem-solving and planning team, referred to as the M G T eam, was also developed in 1997. This team was originally created to work with the state M G coordinator in identifying and resolving the problems resulting from the 1996 shift in management. In its first year, the team was instrumental in initiating the VCE M G administrative Website, contributing to the development of the VCE Master Gardener Coordinator M anual (D orn and Relf, 1998b), and planning M G College, a special advanced-training opportunity extended to active VCE $M$ Gs held annually on the campus of VirginiaT ech. M ore recently, theteam has addressed risk management issues facing $M G$ programs by developing two training slide sets for coordinators (Reilly and Carter, 1998a, 1998b); volunteer recognition tools, such as VCE nametags and service awards; and educational programming across VCE program areas, such as 4-H and family and consumer sciences (FCS). The M G team continues on a year-toyear basis, identifying new individuals who will bring unique and valuable perspectives to the team's discussions. Team representatives include locally funded agents, state-funded agents (environmental horticulture, $4-\mathrm{H}$, and FCS), locally funded nonagent coordinators, volunteer coordinators, M G volunteers, and representatives of the Virginia $\mathrm{M}$ aster $\mathrm{G}$ ardener A ssociation (VMGA).

\section{New management guidelines}

A new management guide, the VCE Master Gardener Coordinator M anual (D orn and Relf, 1998b), was developed cooperatively with teams of MG volunteers, local coordinators, agents, and paid VCE staff to build structure and uniformity in M G program management across the state of Virginia and to enhance the effectiveness of the local coordinator. The management topics identified by this group ranged from recruiting for predetermined job descriptions to recognition proceduresfor volunteers. Contemporary volunteer management to $p$ icswere researched to provide the basis for the new management guide. Local M G programs were asked for samples of letters, tests, training outlines, and procedures that were used to manage their M G programsfor inclusion in the coordinator's manual. The M G T eam reviewed the existing management guide, the volunteer chapter in the Virginia Master Gardener $\mathrm{H}$ andbook 
T able 2. Local Virginia C ooperative Extension M aster $\mathbf{G}$ ardener coordinators' evaluation of available management tools for assisting and directing volunteer program management.

\begin{tabular}{lcc}
\hline T ool & $\mathbf{N}^{\mathbf{z}}$ & ${\mathbf{U ~ s e f u l ~}(\%)^{\mathbf{y}}}^{\mathbf{y}}$ \\
\hline M anual & 39 & 92.3 \\
Training & 35 & 80.0 \\
Consultation & 33 & 78.8 \\
Website & 34 & 55.9
\end{tabular}

${ }^{\mathrm{z}} \mathrm{N}$ represents the number of responses to the particular question. The changes in $\mathrm{N}$ reflect those respondents who selected not to answer the question.

y ndividuals responded to a scale of 1 to 4 , with two answers representing acceptable levels and two not acceptable levels. Percent usefulness was determined by adding the frequency percentages of the two acceptable levels.

(Relf, 1994), and an outline for M G program policies and guidelines that were developed in 1993 by a team of 12 agents, volunteers, and state-level staff. Pertinent information served as the basis for development and new sections were added to reflect the current management situation. To provide coordinators with a clear understanding and the information to train M G volunteers, new management guidelines fully explained the mission of VCE, its Environmental H orticulture Plan of Work and related importance of record keeping and reporting, and the role of the extension agent and the local MG coordinator. As the manual was developed, sections were reviewed by the M G team for applicability. A 14-chapter draft version was completed in M arch 1998 (Table 1).

\section{Inservice for training local coordinators}

Local MG coordinator training sessions are conducted annually to review M G program management. The M G Team helped to makethe decision that coordinator training will be held annually in June, just before M G College. Because the majority of coordinators are volunteer positions that experience yearly turnover through reelection, it is necessary to have an annual training event to familiarize these individuals with their jobs and the resources available to assist them. The M G T eam advised that J une was an appropriate time for the training, as most local officer elections occurred in thespring and new coordinatorswould be in place to participate in a June training. 0 ther regional training op- portunities are offered as need arises.

\section{VCE-MG program administrative Website}

An administrative Website on the VCE I ntranet (nonpublic domain) was developed for use by local coordinators and VCE administrators. The Website includes current VCE MG program policies; educational resources, such as lists of slide sets, video tapes, and publications, that can be used to train MGs and educate the general public; a calendar of events reflecting possible recertification training opportunities for M G volunteers; frequently asked management questions and their answers; past issues of the Virginia M aster Gardener LeadershipD evelopment $N$ ewsetter; and other timely pieces of information, such as conference registration announcements and forms, teaching tools, and articles.

\section{VCE-MGC coordinator Listserv}

To facilitate direct communication between the state and local M G coordinators, an electronic discussion list, a listserv, was instituted with signon controlled by the state M G coordinator. Coordinator's personal or unit office e-mail addresses are subscribed to the list, which is updated as coordinator changes occur. The state coo rdinator uses the list to send information in a timely manner, such as recertification training opportunities; grant applications; or reminder of management tasks, such as submitting MG service awards.

\section{The state MG newsletter message}

To reinforce the change in expectations of M Gs, the statewide newsletter for M G volunteers, the Virginia Master Gardener Leadership D evelopment $\mathrm{N}$ ewsletter, edited by the state M G coordinator, was refocused on topics that developed leadership skills in its readers. Past issues of the newsletter were used as recognition tools, praising individuals for accomplishments. Since 1996, the newsletter has focused on the role of M G volunteers in leading educational programs in Virginia communities. It regularly includes resources available for $M G$ s to do their jobs, such as grants, publications, and web sites; examples of edu- cational programscurrently conducted by VCE M Gs; program administrative information, such as planning for the Advanced M G Stewardship series; and a calendar of events that lists recertification training opportunities. Each individual who trains as a VCE MG receives a complimentary subscription to the newsletter as long as the individual remains an active $\mathrm{M} \mathrm{G}$.

\section{Tools to train MG volunteers}

Tools to train M G volunteers are available to local coordinators. The Virginia Master Gardener $\mathrm{H}$ andbook is the base text for initial training, covering 16 horticulture topics and volunteerism. Slide setsand video tapes are available on loan to supplement the training manual. 0 pportunitiesto support retention of volunteers include MG College, advanced training offered annually at the university; the Advanced M aster Gardener Stewardship series, such as M aster $G$ ardenerTree Steward (D ay et al., 1996) and $M$ aster Gardener-Water Steward (D orn et al., 1997); and regional training supported by the Office of Environmental $\mathrm{H}$ orticulture.

\section{Future management tools}

Additional support for local M G program management is under development. An Internet-based record keeping and reporting system, designed by a special project team of agents, volunteers, and the state M G coordinator, is being developed. The new system will facilitate record keeping for individual volunteersas well as M G projects, reinforce the connection of M G projects to VCE'sE nvironmental $\mathrm{H}$ orticulture Plan of Work, and place responsibility on VCE agentsto incorporate M G accomplishmentsin VCE's annual reports.

The M G T eam has identified the need for tools to enable the M G coordinators to more effectively train $M \mathrm{Gs}$ on how to implement educational programs. Providing subject matter training is only the first step in allowing $M$ G s to carry educational programs to the public.

\section{Evaluation of management tools}

In an evaluation survey, respondents ranked the VCE Master Gardener $\mathrm{C}$ oordinator $\mathrm{M}$ anual asthemost 
helpful tool in restructuring the local M G program, followed in order of helpfulness by M G coordinator training sessions, follow-up consultation with the stateM G coordinator and/ or state extension specialist, and finally the VCE MG administrative World WideW eb (Web) site (T able 2). T hese results areas expected, as the manual is a hands-on reference that is always available for immediate consultation. $\mathrm{N}$ ot all individuals evaluating the manual (i.e., those who have started a brand new M G program since 1 J uly 1998) have participated in a coordinator training session. Also, the W eb site is not as popular a resource because all coordinators are not Internet users and because the site does not contain as much information or implementation examples as the manual. While consultation with the state coordinator isan option for many coordinators, it is sometimes difficult to schedule a consultation. Additionally, thistype of appointment lacks the benefit of interaction with other coordinators that comes with group trainings.

\section{Conclusions}

In 1996, there were 2500 active M G volunteers in 39 M G programs spread throughout 67 of 107 unit offices in Virginia. Even with a major shift in management that occurred in 1996, the VCE M G program continues to grow. In 1999, there are 2700 M G volunteers in 45 MG programs spread through 76 of 107 VCE unit offices.

The VCE MG Web page, VCE $M$ aster $\mathrm{G}$ ardener $\mathrm{C}$ oordinator $\mathrm{M}$ anual, the M G T eam, the refocused Virginia $M$ aster Gardener Leadership D evel opment $\mathrm{N}$ ewsietter, and additional M G management training tools were developed to assist and support a structured program management approach that focuses on local M G coordinators and their relationship to VCE staff, agents, and specialists, and the overall health of the VCE M G program. Future focus will address the role of $M G$ volunteers as trainers and assist local coordinatorsin training M Gsto implement educational programs in cooperation with all VCE agents.

\section{Literature cited}

Bobbitt, V. 1997. The Washington State $U$ niversity $M$ aster $\mathrm{G}$ ardener program: C ultivating plants, people, and communities for 25 years. H ortT echnology 7:345-347.

Bradshaw, J . 1997. State M aster G ardener program review. Unpublished data presented at the 5th Annu. Intl. M aster Gardener Conf., Sacramento, Calif.

D ay, S.D., S.T. D orn, P.D. Relf, and J.R. $\mathrm{H}$ arris. 1996. M aster $\mathrm{G}$ ardener-T reeStewards: Advanced training to enhance community volunteerism. HortScience 31(4):595.

Dorn, S.T., M.T. Aveni, and P.D. Relf. 1997. M aster $G$ ardener-W ater Stewards: Advanced training to enhance community involvement. H ortScience 32(3):492.

Dorn, S. and P.D. Relf. 1998a. Welcome to Virginia M aster gardenering! Guide to educational programming and resource and reference guide. VCE Publ. 426-699. Va. Coop. Ext., Blacksburg.

Dorn, S. and P.D. Relf. 1998b. VCE M aster $\mathrm{G}$ ardener coordinator manual. $\mathrm{Va}$. Coop. Ext., Blacksburg.

Jones, G.M. (gmjones@vt.edu). $20 \mathrm{ct}$ 1996. "M aster G ardener co ordination and consumer horticulture." E-mail to extension agents and administration.

Price, M .S. 1997. M aster Gardeners I nternational Corporation-A success story. H ortT echnology 7:336-338.

Reilly, P. and D. Carter. 1998a. Risk management training for VCE M Gs. Va. Coop. Ext., Blacksburg.

Reilly, P. and D . Carter. 1998b. 4-H leadership training for VCE M Gs. Va. Coop. Ext., Blacksburg.

Relf, D. (ed.) 1994. Virginia M aster Gardener handbook. Blacksburg, Va.

Ruppert, K.C., J. Bradshaw, and A.Z. Stewart. 1997. The Florida M aster Gardener program: H istory, use, and trends. H ortT echnology 7:348-353.

Schwab, J.L. and P.D. Relf. 1989. The Virginia Master Gardener management guide. Va. Coop. Ext. Publ. 426-700, Blacksburg.

Dorn, S. and Relf, P.D. (eds.). 1997. VCE MG Program Policies. Va. Coop. Ext., Blacksburg. 